\title{
PATROCINIO Y MECENAZGO: DESDE CAYO CILNIO MECENAS A NUESTROS DÍAS
}

\section{SPONSORSHIP AND PATRONAGE: FROM CAYO CILNIO MECENAS TO PRESENT DAY}

\author{
AUTOR \\ Luis Felipe Solano Santos \\ Licenciado y Doctorando en Ciencias de la Información (Universidad Complutense de Madrid) (España) \\ Ifsolano@yahoo.es
}

\section{RESUMEN}

El presente artículo ofrece la evolución histórica del Patrocinio y Mecenazgo, desde la figura de Cayo Cilnio Mecenas a nuestros días, desde tres perspectivas distintas: los principales mecenas, los acontecimientos o acciones más relevantes y la regulación de dichas actividades por parte de los poderes públicos.

\section{PALABRAS CLAVE}

Mecenazgo - Responsabilidad Social Corporativa (RSC) - Filantropía.

\section{ABSTRACT}

The present article offers the historical evolution of the Sponsorship and Patronage, from the figure of Key Cilnio Mecenas to our days, from three different perspectives: the principal patrons, the events or the most relevant actions and the regulation of the above mentioned activities on the part of the public power. 


\section{KEY WORDS}

Patronage - Corporate social responsibility - Philanthropy.

\section{ÍNDICE}

\section{Origen del Mecenazgo}

2. Mecenas: Trajano, Alfonso X el Sabio, Lorenzo de Médici, Alejandro VI, Felipe II...

3. Filantropía, Fundaciones y Regulación

4. Conclusiones

\section{Origen del Mecenazgo}

Cayo Cilnio Mecenas nació hacia el año 60 a. de J. C. y murió en el año 8 antes de la era cristiana. Confidente del emperador romano Augusto y protector de los poetas Horacio y Virgilio, Mecenas descendía de una antigua familia etrusca y fue uno de los más antiguos partidarios de Octaviano. Su adhesión al monarca y una extraordinaria condición para los negocios le convirtieron en uno de los próceres de la época. Incluso medió durante la guerra civil para la reconciliación de las partes beligerantes, no en vano era quien dirigía los asuntos del Estado en ausencia de Octaviano. Además acompañó a Augusto en las batallas de Módena, Filipos, Perusa, Perola y Accio; y estuvo encargado del gobierno provisional de Italia durante tres años. Digamos que ejerció bastante influjo en el ánimo del emperador y en varias ocasiones le aconsejo conservar el poder que quería abdicar. Dicen que era sencillo y humilde por temperamento y carácter. Destacar que rehusó todo cargo público contentándose con el título de caballero romano para así disfrutar de los goces de la vida. En el campo artístico, Mecenas aspiró a los laureles del poeta, algo que no logró a causa del excesivo ornato del estilo. 
Sin embargo, Mecenas ha pasado a la posteridad como sinónimo de generosidad para los cultivadores de las letras. Dedicó buena parte de su fortuna a proteger y a apoyar a escritores y artistas como los citados anteriormente. Ambos poetas no dejaron de testimoniar en sus versos la gratitud que le debían y el afecto que le profesaban.

Este ciudadano romano no sólo está considerado el primer mecenas de la historia, sino que gracias a él nace históricamente el mecenazgo, de ahí su denominación, o lo que es lo mismo la protección de las artes y la cultura, es decir, el patrocinio cultural y, por ende, la responsabilidad social.

\section{Mecenas: Trajano, Alfonso X el Sabio, Felipe II, Lorenzo de Médici, Alejandro VI...}

Casi dos siglos después la figura de Trajano, emperador de Roma, se erige entre las demás en el ámbito del mecenazgo. El español defiende las aptitudes de varios artistas y arquitectos más sobresalientes del momento como, por ejemplo, Plinio el Joven, escritor latino y sobrino de Plinio el Viejo, considerado como el mejor naturalista de la antigüedad. Plinio el Joven destacó en poesía, pero la mayor parte de sus escritos se han perdido. Era también conocido por sus dotes como orador, considerándose seguidor de Cicerón. Además participó en muchos juicios, pero el único discurso que se conserva es su Panegiricus Trajani, descripción aduladora y enfática de la figura de Trajano, que es un instrumento valioso para estudiar diversas acciones que hizo el emperador español en campos administrativos como impuestos, justicia, disciplina castrense y comercio. Plinio lo definía como un tratado sobre el gobernante perfecto.

Por otro lado, Trajano fue un gran precursor arquitectónico y prueba de ello son el Templo de Trajano, el de Kom Ombo, Denderah y Esnah, construcciones egipcias sobre las que influyó enormemente. Además no sólo construyó, sino que preservó y 
restauró multitud de monumentos, sobre todo religiosos, que de lo contrario hubiesen desaparecido casi con toda seguridad con el paso del tiempo.

A partir de entonces son muchos los próceres y adinerados que optan por invertir parte de sus fortunas en las distintas disciplinas artísticas obteniendo así popularidad $y$, por supuesto, una extraordinaria imagen de cara a la sociedad.

Otro gran mecenas fue Alfonso X el Sabio, rey de Castilla y León desde 1252 a 1284. Hijo de Fernando III el Santo y de Beatriz de Suabia, este ilustre personaje recibió una esmerada educación tanto científica como literaria y militar. De ahí que se convirtiera en uno de los principales impulsores de la cultura durante el siglo XIII en España. Famoso es su código legislativo de Las siete partidas, obra calificada de monumento colosal y núcleo hasta los tiempos presentes de la legislación española, ya que con ella Alfonso X se adelantó en al menos cinco siglos a su tiempo. Pero la cosa no queda ahí, puesto que la creación literaria es también de carácter lírico, histórico, científico y recreativo. Alfonso X patrocinó, supervisó y a menudo participó con su propia escritura y en colaboración con un conjunto de intelectuales latinos, hebreos e islámicos conocido como Escuela de Traductores de Toledo, en la composición de una ingente obra en prosa que inicia en buena medida la prosa en castellano.

Pocos siglos después, concretamente, en el siglo XV los Médici se convierten en los grandes mecenas no sólo de la época, sino de buena parte de la historia. Lorenzo el Magnífico, príncipe de Florencia, es la figura más importante en este sentido. Destaca por el apoyo a artistas de la talla de Sandro Botticelli, Leonardo da Vinci, Giuliano da Maiano y Miguel Ángel Buonarroti, entre otros. Además se encargó de extender la obra renacentista italiana por el resto de las cortes europeas gracias a sus excelentes relaciones. Fundó, entre otras instituciones, la Biblioteca Laurenciana. 
Gracias a la generosidad de los Médici y otros mecenas como veremos a continuación, Miguel Ángel ha pasado a la historia, no sólo como el artista más completo, sino como el mejor pagado de todos los tiempos. Obras del calibre de La Piedad o David, los frescos y pinturas de la Capilla Sixtina, la fachada del Capitolio, en Roma, o el vestíbulo de la Biblioteca de Florencia no existirían sin el apoyo de estos mecenas.

Curiosamente es en 1492, fecha en la que fallece Lorenzo el Magnífico, cuando podría decirse que nace el denominado por algunos autores Patrocinio Internacional de Estado. Se trata, cómo no, de la inversión que realizan los Reyes Católicos para financiar el viaje de Cristóbal Colón que desembocó en el descubrimiento de las Américas.

Casi al mismo tiempo, al poco de unos años, en la península itálica los Borgia, así como los papas Julio II o León $\mathrm{X}$ recogen el testigo que se encontraba en manos de los Medici y continúan una labor excepcional como es la de proteger el arte de figuras como Miguel Ángel, Leonardo da Vinci, Rafael y Bramante, entre los que existían importantes diferencias y desavenencias.

Entre los Borgia, el papa Alejandro VI es el máximo exponente como mecenas, no en vano encargó a Miguel Ángel la fundamental reconstrucción de la basílica de San Pedro y mandó levantar el edificio principal de la Universidad de Roma. Además apoyo a otros artistas de la talla de Tiziano o el Bosco.

En España se erige como mecenas de las artes Felipe II, conocido como el rey Prudente. El Escorial es la prueba más palmaria de su labor como protector de las artes y la cultura. Pero la cosa no queda ahí, puesto que el monarca elaboró una política de patrocinio a través de una relación muy directa con los artistas, estructurada a través de la Junta de Obras y Bosques, la llamada Congregación en El Escorial o el Consejo de Arquitectura. 


\section{Filantropía, Fundaciones y Regulación}

Algunos autores aseguran que es en el siglo XVII cuando aparece la figura del Filántropo. La Real Academia Española de la Lengua define dicha denominación como persona que se distingue por el amor a sus semejantes y por sus obras en bien de la comunidad. Por entonces, la filantropía estaba dirigida a la protección de los más desfavorecidos, es decir, a la gente pobre y enferma.

El 20 de junio de 1849 se aprueba en España una de las disposiciones más antiguas de las que todavía se encuentran formalmente en vigor en el ordenamiento español: la Ley General de Beneficencia que constituye el punto de partida de la regulación sobre las fundaciones.

Si el Código Civil es la piedra angular del derecho privado de las fundaciones, el Decreto e Instrucción de 14 de marzo de 1899 lo es del régimen jurídico-público de las fundaciones asistenciales, puras y mixtas. Indudablemente, la norma marcó toda una época en la regulación de tales entidades. Sin embargo, se trata de una disposición que necesariamente, y sin más demora, debe ser sustituida por otra que se adapte a la nueva realidad de las fundaciones.

Ya en el siglo XX, concretamente en 1913, el judío Ivy Ledbetter Lee, considerado el padre de las RR.PP., es el responsable intelectual de la creación de la fundación americana Rockefeller, modelo histórico de mecenazgo para el resto de fundaciones venideras.

John Davison Rockefeller no sólo fue un gran hombre de negocios, sino que se convirtió en el gran filántropo. Tras la jubilación se dedica a invertir grandes cantidades de dinero para la creación 
Por otra parte, junto a las anteriores disposiciones, que configuran la regulación general de las fundaciones, otras muchas normas se refieren asimismo a importantes aspectos relacionados con ellas. Así, puede citarse el Real Decreto de 20 de julio de 1926, de instituciones y fundaciones benéficodocentes particulares de enseñanza agrícola, pecuaria o minera; el Decreto 446/1961, de 16 de marzo, de fundaciones laborales; las previsiones contenidas en las leyes fiscales en relación con los beneficios fiscales que se les reconocen; los Decretos de 1923 y 1928 sobre enajenación y arrendamiento de bienes de fundaciones, o las recientes disposiciones sobre contabilidad y rendición de cuentas de fundaciones asistenciales.

En España habría que esperar más de cuarenta años para ver nacer la primera fundación. El 4 de noviembre de 1955 el financiero español Juan March Ordinas creaba la Fundación Juan March como entidad cultural y benéfica de carácter privado. Desde entonces la institución se ha distinguido por un extraordinario apoyo a las actividades culturales, sociales y de investigación.

Volviendo a las disposiciones legales señalar que la Instrucción de 1899 citada con anterioridad queda diluida al aprobarse el Decreto 2930/1972, de 21 de julio, dictado en desarrollo de lo dispuesto en el artículo 137 de la Ley General de Educación, de 4 de agosto de 1970. Este reglamento es aplicable sólo a las fundaciones culturales v docentes.

También en la década de los setenta, concretamente en 1976, se crea la Fundación Ramón Areces, una de las más importantes de nuestro país. Se trata de una institución cultural de carácter privado dedicada principalmente al fomento de la educación y la investigación científica y técnica, cuyo origen se encuentra en El Corte Inglés. La actividad comercial se remonta a 1890 en la calle de Rompelanzas (hoy Preciados) como tienda de sastrería de ropa de niños. Allí se "cortaban" las telas para hacer la confección. El dueño, Juan Gordo de Centenera, se la vendió a Ramón Areces por 150.000 pesetas. Areces, que había sido emigrante en Cuba, tomó la idea 
de un gran almacén cubano (El Encanto), donde había sido aprendiz. El Corte Inglés nace con siete empleados y hoy, con más cien mil, tiene sucursales en muchas ciudades españolas y algunas en el extranjero, como en Portugal (en Lisboa y en Oporto). Actualmente es un conjunto de empresas diversas.

Año también importante es el de 1985, puesto que se aprueba la Ley del Patrimonio Histórico Español, que recoge una serie de incentivos fiscales en el campo del Patrimonio, concretamente, en el Título VIII denominados "medidas de fomento".

En 1986 se celebra en Francia el I Mercado Internacional de la Espornsorización y el Mecenazgo (SPONCOM). Cada uno de los países de la Comunidad Económica Europea participantes se comprometieron a fomentar el mecenazgo. Además el encuentro sirvió para desarrollar y analizar las diferentes herramientas de comunicación del patrocinio.

Dos años después se celebra la segunda edición, se aprueba la Ley 34/1988 de 11 de noviembre, "Ley General de Publicidad" y la multinacional Coca Cola se convierte en el líder mundial en patrocinio deportivo gracias a la alta inversión realizada en las Olimpiadas de Seúl.

A partir de esa fecha comienzan a proliferar las fundaciones, así como las inversiones en patrocinio, mecenazgo y esponsorización hasta que en 1991 se redacta el proyecto de Ley del Mecenazgo, en España.

Un año después, en 1992, la celebración de las Olimpiadas de Barcelona, la Expo de Sevilla, el V Centenario del Descubrimiento de América y Madrid Ciudad Cultural ponen de manifiesto la importancia que ha adquirido el patrocinio no sólo en nuestro país, sino en todo el mundo. 
En relación al V Centenario cabe destacar la informatización del Archivo de Indias, una de las actividades de mecenazgo más importantes de los últimos años llevada a cabo por las empresas IBM y El Corte Inglés.

Dos años después se aprueba en España la Ley de Fundaciones y de Incentivos Fiscales a la Participación Privada en Actividades de Interés General, concretamente el 24 de noviembre de 1994, con objeto de regular y garantizar las actividades de patrocinio y mecenazgo que las instituciones, es decir, fundaciones llevan a cabo.

Se trata de dar una respuesta eficaz a la necesidad ineludible de actualizar la legislación sobre fundaciones que viene determinada, de un lado, por el artículo 34 de la Constitución, que reconoce el derecho de Fundación para fines de interés general con arreglo a la Ley, y, de otro lado, por la importancia que en la vida social ha adquirido el ejercicio del indicado derecho de Fundación. La reserva de Ley sobre este derecho es establecida por el artículo 53 del texto constitucional.

Además, la nueva norma pretende estimular la iniciativa privada en la realización de actividades de interés general. Como la primera, también esta necesidad de estímulo es ineludible, vistos la dificultad de los poderes públicos de atender plenamente ese interés general y el protagonismo que la sociedad reclama y entrega a las variadas entidades sin ánimo de lucro.

Ambas necesidades son atendidas de manera uniforme en la presente Ley, lo que se justifica en la evidencia de que, tanto una regulación actualizada sobre fundaciones, como un régimen de incentivos fiscales a la participación privada en actividades de interés general son soluciones a un mismo problema: dotar al campo de las actuaciones altruistas de una base jurídica fomentadora y ajustada a la actual demanda que la sociedad presenta. 
Se ha afirmado que esta ley puso fin a un régimen regulador de las fundaciones que cabría calificar de vetusto (algunas de sus normas databan de mediados del siglo XIX), fragmentario, incompleto y aun contradictorio, satisfaciendo las legítimas demandas y aspiraciones reiteradamente planteadas por el sector, y adaptando, en suma, esta normativa a las exigencias del nuevo orden constitucional, singularmente en lo que se refiere al sistema de distribución de competencias entre el Estado y las Comunidades Autónomas.

\section{Conclusiones}

Indudablemente el Patrocinio y Mecenazgo se han convertido con el paso del tiempo en técnicas de Relaciones Públicas, herramientas de creación de imagen e instrumentos de Responsabilidad Social Corporativa. Lo que un principio se identificaba como filantropía ahora se identifica como Responsabilidad Social Corporativa, que, como define el profesor Luis Solano Fleta, es el conjunto de obligaciones inherentes a la libre asunción de un estado o condición, aun no tipificado por el ordenamiento jurídico positivo, pero cuya fuerza vinculante y previa tipificación, proceden de la íntima convicción social de que su incumplimiento supone la infracción de la norma de cultura. Entendemos por norma de cultura ese conjunto de convicciones morales conquistadas a lo largo de la historia y que se relacionan con los grandes valores, lo que Sorokin denomina el universo de lo supraorgánico. Pues bien, las acciones de Patrocinio y Mecenazgo forman parte de ese conjunto de obligaciones que se derivan del extraordinario impacto que una organización, ya sea privada o pública, tiene sobre la sociedad a todos los niveles, es decir, político, económico, medioambiental... 


\section{Bibliografía}

ANDRES, A. de J. (1993). Mecenazgo y Patrocinio. Madrid: Editmex.

ALBERTO PÉREZ, R. (1989). Estrategia publicitaria y de las Relaciones Públicas. Madrid: UCM.

COSTA, J. (1995). Comunicación corporativa y revolución de los servicios.

PARES I MAICAS, M. (1994). La nueva filantropía y la comunicación social: mecenazgo, fundación y patrocinio. Barcelona: Promociones y Publicaciones Universitarias

SOLANO FLETA, L. (1995). Fundamentos de las Relaciones Públicas. Madrid: Síntesis. 